\title{
Applications of Leaky-wave Antennas: A Review
}

\author{
Hafiz Suliman Munawar \\ University of New South Wales (UNSW) Sydney, Australia
}

Received: 06 January 2020; Accepted: 08 March 2020; Published: 08 June 2020

\begin{abstract}
This review discusses some of the widely used applications of Leaky-wave antennas (LWA) along with their certain types. LWAs have been used extensively in various fields since their origin in the 1940s. They provide wide range of applications that include radars, human sensors, imaging and satellite communication. These antennas have advantage of frequency scanning in a single sweep which make them better choice for frequency scanning applications. Different techniques are integrated with them which increase their importance by providing ease of fabrication and low-profile system. In addition to discussing different types of LWA, this paper contains a comparative analysis of these types which helps in providing a clear knowledge of how and where these antennas can be used. Most of the antenna parameters have a tradeoff between gain and radiation patter, for which careful evaluation of these parameters is needed to make a choice for antenna. Slight modification in the antenna renders great increase in its performance or sometimes degrade it as well. LWA are used for $5 \mathrm{G}$ applications which is the latest trend and has great potential of development in coming years. Recent advances in LWA put emphasis on attaining radiations at the broadside which is a challenge for them. The challenges and possible future directions which can draw from existing data have been briefly discussed in this review. To form this review, 15 papers from last 6 years are considered which discusses various parameters of these antennas like radiation pattern, directivity and their fabrication complexities.
\end{abstract}

Index Terms: Millimetre wave, leaky-wave antenna, micro strip antenna, beam steering, high gain antennas.

(C) 2020 Published by MECS Publisher. Selection and/or peer review under responsibility of the Research Association of Modern Education and Computer Science

\section{Introduction}

With the rapid of growth of wireless communication, antennas became more and more popular because of their enormous applications in wireless communication networks [1]. Many different types of antennas are

* Corresponding author

E-mail address: h.munawar@unsw.edu.au 
developed and are still developing with great speed. For many years leaky-wave antennas have been considered as a very useful research topic [2]. Ever since the origin of LWA, there has been rapid increase in their use and manufacturing. Many advancements have been made to gain advantage of these useful antennas in various fields [3]. With the emergence of metamaterials in recent years, researchers have shown great interest in the field of LWA for further development.

LWA fall under the category of travelling wave antenna which work by scanning the main beam with frequency sweep. LWAs propagate by using the guiding structures along the length of their structure and modes of propagation control their radiation pattern. These antennas are best suited for the applications in which there is an edge of frequency beam scanning. LWAs are usually smaller in size which makes them very useful for installation in aircraft system as they have confined space. Various applications such as inter vehicle communication, human tracking, and direction of arrival estimation use LWAs because of their simple feeding design [4]. One of the many features of LWA is that a wave is used to excite their electromagnetic field that lead to the production of current.

Synthesis of LWA is done using many different types of architectures and technologies, one of which is the use of planar superstrate. In this type, antenna structure is made over the ground plane by a partially reflective surface and is excited by small radiators [5]. LWAs are also designed using dual stubs which provide consistent gain and broadband impedance matching [4]. Antennas with micro strip lines as their feeding structure are called micro strip leaky wave-antennas (MLWA) and they have gained much popularity because of their simple integration, cost efficient, low profile and high gain capabilities $[4,6]$. Another type of leaky-wave antenna is the periodic leaky-wave antenna (P-LWA) which provides the advantage of backfire to end fire scanning but suffers from degradation issue for broadside radiation [6].

Use of LWA has been extended to fulfil the purpose of shaping radiation pattern which is carried out by gain enhancements and side lobe reduction [5].

1.1 Theory of leaky-wave antenna

Leaky waves are travelling waves which move along the length of guiding structure. In presence of slits and apertures, these waves leave the structure and radiate freely in space. At the other end this energy is absorbed by a matched load, $90 \%$ of the energy is lost during this travel.

The review paper is organized into sections. Section II will provide brief review of the existing technologies and methods that are used in leaky-wave antennas to have a clear view of the topic. Section III discusses some of the applications of the leaky-wave antennas. Section IV include a comparative analysis of some LWAs. Lastly, Section V concludes the review.

\section{Methodology}

The radiating mechanism of leaky-wave antennas is the use of travelling wave on guiding structure that leaks out of a radiating aperture. These antennas have some advantages over other antennas which includes simpler design and no feeding network.

As the field of leaky-wave antennas is vast and many researches are done on this topic, so it is needed to set the boundary and scope of this review. This review contains papers published in the conferences and journals from International Electrical and Electronics Engineers (IEEE) and Institution of Electrical Engineering (IET) in last 6 years which cover the topics related to LWA and its applications.

This section will discuss some of the leaky-wave antenna designs which are used in many different applications

\subsection{Surface based leaky-wave antennas}

Surface waves (SW) may be bounded to a surface or may be present as an interface between two materials. Use of SW has great importance in electromagnetics which makes them useful in radar applications. Ma et al [7] designed one such leaky- wave antenna which is excited by collimated surface-waves. 
Antenna consisted of two surface-wave launchers (SWL) along with a high impedance surface for which feed is provided by a planar horn. SWL uses substrate integrated waveguide which relates to a linear tapered micro strip. Antenna performance showed that it can easily provide good gain values along with a stable radiation pattern. These results make them useful in radars and satellite communications [7].

\subsection{Leaky-wave antenna using dual-stub elements}

The paper presented by Shaw et al [4] contained the design of LWA with 16 elements array. In order to have consistent gain and pencil beam radiation, the array of antenna was in X-band. Metal stubs present at the top were complementary in nature to the bottom slots. This arrangement provided broadband impedance matching. Obtained results from the designed antenna showed that dual-stub arrangement with complementary arrangement provides consistent gain. Pencil beam pattern and high value of gain showed that these antennae have application in imaging [2].

\subsection{Leaky-wave antenna with 1-bit coding}

Chen et al [1] gave a novel design of LWA that consisted of 1- bit metamaterials. Top layer of the coding metamaterials unit was a coplanar waveguide whereas the bottom layer was of micro strip line in addition to two metal rows that are drilled on each side of the unit. Resonators were excited by the magnetic field generated by the guided wave. The antenna related to 20 switches and beam directions are changed by altering the states of diodes. Simulation results showed fixed frequency beam steering along with providing high directivity [1].

\section{$2.4 \mathrm{Ku}$-band leaky-wave slot array antenna}

Gap waveguide technology is used in many antenna designs which increase their radiation pattern providing application in millimeter wave band. Waveguide structures are made by screwing two metallic plates together forming artificial magnetic conductor [7].

Design of a low loss leaky-wave slot antenna which operated in Ku-band was presented by Hamedani et al [8] that used gap waveguide technology for its Feeding system. Different parts of the antennas were designed individually which includes the design of ridge gap waveguide, designing linear slot array and planar slot array and are arranged together to form the complete antenna. Results obtained from the designed antenna showed high gain and the ability to scan frequency using broadside coverage.

\subsection{Symmetry leaky-wave antenna}

LWA has a great scope of application in various fields that include vehicle radars, surveillance and point to point communication because of their advantage of beam-scanning. The ability of LWA to reduce the complexity of many systems provides facilities in many applications. One advanced form of LWAs are the PLWAs which provide good scanning capabilities but have the issue of open-stop band. This issue arises because of the instability of gain and efficiency during the broadside scanning [6].

Many different techniques were implemented in order to nullify the effects of open-stop band. One such type of LWA was designed by Guo et al [6] which used symmetric micro strip patches along coupled lines. A symmetric, rectangular patch with half wavelength was attached with coupled lines on each side having quarter wavelength. Feed is provided by any of the coupled line that performs the excitation. The proposed design of the antenna provided a wide band in the operating frequency which supported its use in applications that require frequency scanning through the broadside. 


\subsection{Truncated leaky-wave antenna}

Another synthesis method of LWA is using planar superstrate which generates cosecant-radiation pattern. These radiations are useful in applications that require power flux illumination for specific range of angles [9].

An antenna design for the purpose of generating cosecant radiation was presented by Scattone et al [5]. The antenna was configured by a truncated superstrate that was fed on the ground by an open-ended square waveguide. Goal of this design was the formation of main beam pointing at $\theta=-23^{\circ}$. Validation for the presented model was done by full-wave simulations that operate at X-band. Obtained radiation pattern from the antenna were found within $6 \%$ of the relative bandwidth.

\subsection{Circularly polarized leaky-wave antenna}

Circularly polarized antennas have gained much popularity in recent years because they are less affected by Faraday rotation. They can easily reduce the issues of mismatch polarization and interference occurrence from multiple paths which make them highly useful in millimeter-wave applications [10].

Design for circularly polarized periodic LWA was given by S'anchez-Escuderos et al [9] in which Planar Goubau Line (PGA) was used as a power distribution line. PGL lines have advantage over micro strip lines as there is no ground in PGL. The designed antenna had 16 perturbations placed alternatively on each side of the line. Results obtained from the measurements of this designed antenna were good in $38-41 \mathrm{GHz}$ frequency band with radiation efficiency above $90 \%$. This antenna provides various applications in radar because of their frequency steering ability.

\section{Applications of leaky-wave antennas}

Leaky-wave antennas gained much popularity in various fields because of their beam steering ability. As conventional beam steering by use of switching techniques had a lot of problems of cost, complexity and performance loss so leaky-wave antennas based on High Impedance Surface (HIS) [11] addressed these problems. With the emergence of metamaterials in recent years, use of antennas in various applications increased many folds, some of these applications, particularly those reflecting the most recent technologies and needs of the time are discussed in this section.

\section{$3.15 G$ communication systems}

5G systems are the latest addition to the cellular networks which enhances the precious generation facilities. Various antenna techniques were used to increase the performance of this latest technology and are still developing. In addition to the conventional bands, $5 \mathrm{G}$ also requires high frequency bands in millimeter wave range to achieve wider bandwidth. Making use of the beam steering advantage of LWA, an antenna was designed by Rabbani et al [10]. This antenna design is based upon HIS and partially reflective surface (PRS) which are very useful in millimeter wave applications. Integration of beam steerable LWA with PRS layers make them useful for $5 \mathrm{G}$ mobile communication.

\subsection{Low cost radars}

Different kinds of radar are developed over the course of many years which are used in detecting and locating different objects that may be spacecrafts or ships. For the improvements in radars efficiency many kinds of antennas are developed which also includes certain LWA [11]. 
Inherent beam steering property with frequency sweep of LWA make them a good choice for the frequency scanning radar. For the development of a cost-efficient radar, Karamokar et al [11] presented a planar leakywave antenna. The designed antenna was low profile hence proved useful for low-cost radars systems.

\subsection{Human tracking}

One of the most important applications of antennas in general is their use in human tracking. Tracking a human body plays significant purposes in security and surveillance services [12]. Owing to this importance, advancements in technology are made and are still growing. One of the main issues that occurs during the human tracking is the changes in indoor and outdoor environment that effect the performance [13].

Multi strip LWA are used in the tracking process using its ability to estimate and range simultaneously in a single frequency sweep. The antenna design presented by Yang et al [12] performed tracking in range-azimuth plane with high refresh rate to generate images. Wide variety of microstrip leaky-wave antennas (MLWA) with certain modifications such as radar cross section and transverse resonance methods are used to track humans.

Apart from these applications, LWA are used in automotive radars, imaging, MIMO applications. MLWA are used extensively in spacecrafts because of their small size and ease of fabrication. This can efficiently be employed in technology used for identifying disaster struck areas, where rescue tasks are to be carried out. Disaster relief missions rely on state-of-the-art technology, which can be achieved by employed the LWA for tracking humans carrying out the rescue tasks and thereby also gaining data regarding the number of people stuck in an area [14]. Backing up the systems with version management software can further enhance and upgrade the task of human tracking [15] and possibly make the overall process highly efficient.

\section{Analysis and Discussion}

As previous sections covered some of the designed LWA that are developed over the course of time along with some application of these antenna in various fields. It is evident from the studies, that they provide the best choice for the low-profile applications. These described antennas have certain tradeoffs in their parameters which are needed to be evaluated according to the application. For clear understanding of different types of LWA, Table 1 contains a comparative analysis of them. Comparing the merits and demerits of each antenna can provide a clear direction of areas of improvements and the possible applications that can be extracted from each type.

Most of the LWAs are used in application that are dependent on frequency scanning and provide high gain values. Antenna development has increased tremendously by incorporating metamaterials in it, not only they reduce the size of the antenna efficiently but also increase its performance.

Table 1. Comparative Analysis of Some Leaky-wave Antenna

\begin{tabular}{|l|l|l|c|}
\hline Antenna Types & Merits & Demerits & Applications \\
\hline $\begin{array}{l}\text { Surface Based } \\
\text { Leaky- Wave } \\
\text { Antenna }\end{array}$ & $\begin{array}{l}\text { Stable radiation pattern, Good } \\
\text { gain value }\end{array}$ & $\begin{array}{l}\text { Open stopband effect may be } \\
\text { present }\end{array}$ & $\begin{array}{l}\text { Radars and satellite } \\
\text { communications }\end{array}$ \\
\hline $\begin{array}{l}\text { Dual Stub Element } \\
\text { Leaky-Wave } \\
\text { Antenna }\end{array}$ & $\begin{array}{l}\text { Pencil beam radiation pattern, } \\
\text { High value gain }\end{array}$ & $\begin{array}{l}\text { Complementary dual-stub } \\
\text { configuration is needed in micro } \\
\text { strip lines }\end{array}$ & Imaging \\
\hline $\begin{array}{l}\text { 1-Bit Coded Leaky- } \\
\text { Wave Antenna }\end{array}$ & Low profile, High directivity & $\begin{array}{l}\text { Switches control the far field } \\
\text { pattern which are needed to be } \\
\text { controlled independently }\end{array}$ & $\begin{array}{l}\text { One to many } \\
\text { communication }\end{array}$ \\
\hline
\end{tabular}




\begin{tabular}{|l|l|l|l|}
\hline $\begin{array}{l}\text { Ku-Band Leaky- } \\
\text { Wave Slot Array } \\
\text { Antenna }\end{array}$ & $\begin{array}{l}\text { Frequency scan ability with } \\
\text { broadside coverage, High gain, } \\
\text { reduced size }\end{array}$ & $\begin{array}{l}\text { Distance between slots need } \\
\text { optimization otherwise lead to } \\
\text { grating lobe }\end{array}$ & Vehicle radars \\
\hline $\begin{array}{l}\text { Symmetry Leaky- } \\
\text { Wave Antenna }\end{array}$ & $\begin{array}{l}\text { Overcome open stop band issue, } \\
\text { wideband for operating } \\
\text { frequency }\end{array}$ & $\begin{array}{l}\text { Broadside radiation degradation } \\
\text { problem }\end{array}$ & $\begin{array}{l}\text { Frequency scanning } \\
\text { applications }\end{array}$ \\
\hline $\begin{array}{l}\text { Circularly } \\
\begin{array}{l}\text { Polarized periodic } \\
\text { Leaky-Wave } \\
\text { Antenna }\end{array}\end{array}$ & $\begin{array}{l}\text { Less effected by faraday rotation, } \\
\text { High gain, reduced multipath } \\
\text { effect }\end{array}$ & Cross polarization & $\begin{array}{l}\text { Radars, improvement of } \\
\text { poor communication } \\
\text { link }\end{array}$ \\
\hline $\begin{array}{l}\text { Truncated Leaky- } \\
\text { Wave Antenna }\end{array}$ & Low profile, Easy fabrication & $\begin{array}{l}\text { Size of feed is needed to be } \\
\text { engineered first }\end{array}$ & $\begin{array}{l}\text { Sensors, Frequency } \\
\text { scanning applications }\end{array}$ \\
\hline
\end{tabular}

\section{Conclusion and Future Enhancements}

Owing to the importance and wide use of LWA in many applications, a review of some the antennas is done to understand the basics of these antennas and how they are implemented in certain applications with modifications. This review concludes that one of the best attributes of these antennas is their ability of frequency scanning within single sweep which makes them better choice amongst other antennas for frequency scanning application. In addition to that they have easy and simple fabrication process which is also low in cost which further adds to their value.

This review contains some of the important applications where these antennas play pivotal role, and enhance the performance of the system by providing high gain values. MLWA provide larger bandwidths and narrower beam width which make them useful in millimeter-wave circuits. 5G mobile communication system is the latest trend of this year with huge scope in upcoming years and LWA provided contribution in its development.

Considering the recent trends of technology, LWA has great potential of development and further advances. Many of the advances are now been made which put a lot of emphasis on achieving radiation at the broadside.

\section{References}

[1] Mak, K.M., So, K.K., Lai, H.W. and Luk, K.M., 2017. A magnetoelectric dipole leaky-wave antenna for millimeter-wave application. IEEE Transactions on Antennas and Propagation, 65(12), pp.6395-6402.

[2] Lyu, Y.L., Liu, X.X., Wang, P.Y., Erni, D., Wu, Q., Wang, C., Kim, N.Y. and Meng, F.Y., 2016. Leakywave antennas based on noncutoff substrate integrated waveguide supporting beam scanning from backward to forward. IEEE Transactions on Antennas and Propagation, 64(6), pp.2155-2164.

[3] Chen, X.Q., Wan, X. and Cui, T.J., 2017, October. A novel leaky-wave antenna based on 1-bit coding metamaterial. In 2017 Sixth Asia-Pacific Conference on Antennas and Propagation (APCAP) (pp. 1-3). IEEE.

[4] Shaw, R., Basak, S., Mandal, J. and Mandal, M.K., 2018, July. Leaky wave antenna array using complementary dual-stub radiating elements for consistent gain. In 2018 IEEE International Symposium on Antennas and Propagation \& USNC/URSI National Radio Science Meeting (pp. 1613-1614). IEEE.

[5] Scattone, F., Ettorre, M., Eddo, B., Sauleau, R. and Fonseca, N.J., 2018. Truncated leaky-wave antenna with cosecant-squared radiation pattern. IEEE Antennas and Wireless Propagation Letters, 17(5), pp.841844.

[6] Guo, T., Zhang, Q., Hou, X., Kandwal, A. and Li, B., 2018, March. Symmetry leaky-wave antenna without gain degradation at broadside. In 2018 International Workshop on Antenna Technology (iWAT) (pp. 1-3). IEEE.

[7] Ma, Z.L., Chan, C.H., Ng, K.B. and Jiang, L.J., 2017. A Collimated Surface-Wave-Excited HighImpedance Surface Leaky-Wave Antenna. IEEE Antennas and Wireless Propagation Letters, 16, pp.20822085. 
[8] Hamedani, M., Oraizi, H., Zarifi, D. and Amini, A., 2019, March. Design of Ku-band Leaky-Wave Slot Array Antenna Based on Ridge Gap Waveguide. In 2019 13th European Conference on Antennas and Propagation (EuCAP) (pp. 1-3). IEEE.

[9] Sánchez-Escuderos, D., Ferrando-Bataller, M., Herranz, J.I. and Rodrigo-Peñarrocha, V.M., 2015. Lowloss circularly polarized periodic leaky-wave antenna. IEEE Antennas and Wireless Propagation Letters, 15, pp.614-617.

[10] Rabbani, M.S., Churm, J. and Feresidis, A., 2018. Millimetre-wave beam steerable leaky-wave antenna for $5 \mathrm{G}$ systems.

[11] Karmokar, D.K. and Guo, Y.J., 2017, September. Planar leaky-wave antennas for low-cost radar. In 2017 IEEE-APS Topical Conference on Antennas and Propagation in Wireless Communications (APWC) (pp. 112-115). IEEE.

[12] Yang, S.T. and Ling, H., 2017. Application of compressive sensing to two-dimensional radar imaging using a frequency-scanned microstrip leaky wave antenna. Journal of electromagnetic engineering and science, 17(3), pp.113-119.

[13] Munawar, H.S., Maqsood, A. and Mustansar, Z., 2017. Isotropic surround suppression and Hough transform based target recognition from aerial images. International Journal of Advanced and Applied Sciences, 4(8), pp.37-42.

[14] Munawar, H.S., Zhang, J., Li, H., Mo, D. and Chang, L., 2019, April. Mining Multispectral Aerial Images for Automatic Detection of Strategic Bridge Locations for Disaster Relief Missions. In Pacific-Asia Conference on Knowledge Discovery and Data Mining (pp. 189-200). Springer, Cham.

[15] Munawar, H.S., Khalid, U., Jilani, R. and Maqsood, A., 2017. Version Management by Time Based Approach in Modern Era. International Journal of Education and Management Engineering, 4, pp.13-20.

\section{Author's Profile}

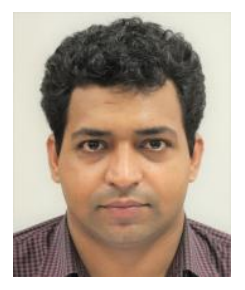

Hafiz Suliman Munawar is a PhD student at the University of New South Wales (UNSW), Australia. He is a multi-disciplinary researcher with experience in machine learning, disaster management and artificial intelligence. Hafiz has several international publications in various journals and conferences and has actively been working on disaster management using machine learning.

How to cite this paper: Hafiz Suliman Munawar, " Applications of Leaky-wave Antennas: A Review ", International Journal of Wireless and Microwave Technologies(IJWMT), Vol.10, No.3, pp. 56-62, 2020.DOI: 10.5815/ijwmt.2020.03.05 